\title{
Design of a mobile aerosol research laboratory and data processing tools for effective stationary and mobile field measurements
}

\author{
F. Drewnick ${ }^{1}$, T. Böttger ${ }^{1}$, S.-L. von der Weiden-Reinmüller ${ }^{1}$, S. R. Zorn ${ }^{1, *}$, T. Klimach ${ }^{1}$, J. Schneider ${ }^{1}$, and \\ S. Borrmann ${ }^{1,2}$ \\ ${ }^{1}$ Max Planck Institute for Chemistry, Particle Chemistry Department, Mainz, Germany \\ ${ }^{2}$ Institute of Atmospheric Physics, Johannes Gutenberg University Mainz, Germany \\ *now at: AeroMegt GmbH, Hilden, Germany
}

Correspondence to: F. Drewnick (frank.drewnick@mpic.de)

Received: 23 February 2012 - Published in Atmos. Meas. Tech. Discuss.: 19 March 2012

Revised: 30 May 2012 - Accepted: 30 May 2012 - Published: 27 June 2012

\begin{abstract}
A compact mobile aerosol research laboratory (MoLa) for stationary and mobile measurements of aerosol and trace gas characteristics was developed at the Max Planck Institute for Chemistry (MPIC) in Mainz, Germany. Major efforts were made to design an aerosol inlet system which is optimized and characterised for both, stationary and mobile measurements using a particle loss modelling approach. The instrumentation on board allows the determination of a multitude of physical and chemical aerosol parameters, for example particle number and mass concentration $\left(\mathrm{PM}_{1 / 2.5 / 10}\right)$, particle size distributions in the diameter range $6 \mathrm{~nm}$ up to $32 \mu \mathrm{m}$, and chemical composition of the sub-micron aerosol. Furthermore, trace gas concentrations of $\mathrm{O}_{3}, \mathrm{SO}_{2}, \mathrm{CO}, \mathrm{CO}_{2}, \mathrm{NO}, \mathrm{NO}_{2}$ and water vapour as well as meteorological parameters like temperature, relative humidity, pressure, wind, solar radiation and precipitation are measured together with various housekeeping parameters. All instruments collect data with high time resolution in the second to minute-range. The measurement platform, as well as data acquisition and handling tools, are optimized for efficient application to various measurement settings. The mobile laboratory is designed to be used for mobile investigation of anthropogenically influenced environments. Possible applications include pollutant mapping, chasing of mobile sources or Lagrangian-type measurements in emission plumes, but also stationary measurements with possible frequent position changes and a well-characterised instrument setup. In addition to the design and features of the mobile laboratory, its inlet system and instrumentation as well as examples of applications of this platform are presented. Challenges associated with such measurements and approaches to extract the desired information from the mobile datasets are discussed.
\end{abstract}

\section{Introduction}

Despite its undoubted significant effects on the Earth's climate, the environment and human health, many aspects of the atmospheric aerosol are still not sufficiently well understood (Solomon et al., 2007; Davidson et al., 2005). This holds especially for basic processes like particle generation and transformation or cloud formation, as well as for more practical issues like the characteristics of anthropogenic aerosol sources or its impact on air quality on different spatial scales.

Common approaches for the investigation of spatial characteristics of the ambient aerosol or for studies of transport phenomena utilise modelling work, remote sensing or multiple measurement stations distributed in an air quality network. As a consequence of limited resources these stations measure only a very small set of air quality parameters and provide data with limited time resolution only, typically 15-, 30 - or 60 min data. In addition the limited number of network stations, especially in rural and remote areas, allows only a very coarse determination of the aerosol distribution, which is often not sufficient if nearby sources are investigated ( $\mathrm{Di}$ esch et al., 2011).

So far for highly time-resolved research-quality measurements of a large variety of aerosol and trace gas parameters field intensive measurements are often set up at the local site of interest, with a temporal setup of state-of-the-art instruments in laboratory containers or available buildings only. This type of setup has the limitation of very low spatial flexibility: the measurement locations for the containers are normally determined weeks or months ahead. Once the initial setup is finished moving of the measurement container or setting up the instruments at a different location is rather 
a question of days or weeks than of hours. In addition, the sampling inlets of such setups are often poorly characterised and rarely optimized for their purpose, resulting in unknown sampling artifacts and transport losses in the inlet system (McMurry, 2000).

The atmospheric aerosol and its local composition can change on timescales of hours down to minutes (Pöschl, 2005). To investigate its characteristics, chemical composition, physical properties and local sources as well as the formation, its transport and transformation processes (Kunkel et al., 2012) within such time scales a highly time-resolved measurement setup with large spatial flexibility is desirable. In order to perform such measurements with both, modern instrumentation and well-known and high measurement quality that meet above needs and requirements, we developed a mobile aerosol research laboratory.

Several ground-based mobile laboratories have been described in the literature. Some of these are designed for stationary measurements only, where electrical power can be supplied externally and are mainly intended for an easy change of the measurement location (e.g., Maciejczyk et al., 2004). Truly mobile measurements (i.e., measuring while driving) demand adequate sampling systems and on-board supply of electrical power for the instruments. While many of the mobile laboratories are based on delivery vehicles (e.g., Bukowiecki et al., 2002; Weijers et al., 2004; Pirjola et al., 2004; Kolb et al., 2004), passenger vehicles (e.g., Wa Tang and Wang, 2006), trucks and trailers (Kittelson et al., 2000; Cocker III et al., 2004a, b) also trains (Belikov et al., 2006; Rinke et al., 2010) have been used as platform for mobile measurements.

The majority of mobile laboratories is used for the measurement of air pollution and composition, often in urban and traffic-dominated environments (e.g., Vogt et al., 2003; Weimer et al., 2009; Mohr et al., 2011). Several research groups have investigated engine emissions of cars and trucks under real-world driving conditions either by chasing vehicles (e.g., Kittelson et al., 2000; Canagaratna et al., 2004; Schneider et al., 2005, 2008; Wang et al., 2009) or by sampling from the own tailpipe (Cocker III et al., 2004a, b). Mobile laboratories have been and are also used for the investigation of megacity air quality (e.g., Herndon et al., 2005; Thornhill et al., 2008; Elanskii et al., 2010) or general atmospheric aerosol processes (e.g., Andronova et al., 2003; Belosi et al., 2006). Rarely individual physical aerosol processes like the re-suspension of road dust (Pirjola et al., 2009) are investigated with mobile platforms particularly designed or equipped for such specific purposes.

Here, we describe the development and design of a mobile aerosol research laboratory (MoLa) for stationary and mobile field measurements of various physical and chemical aerosol and trace gas properties together with the relevant meteorological parameters at high temporal and spatial resolution. This encompasses the layout of the instrumentation, the measurement procedures, the data acquisition, and methods for efficient high volume data processing. Some emphasis is placed upon online chemical particle composition measurements by means of aerosol particle mass spectrometry. The layout of the measurement platform and also the data treatment are optimized such that high-quality data can be generated with minimized and well-known measurement artifacts and uncertainties.

\section{The Mobile Laboratory}

\subsection{Description of the MoLa platform}

The MoLa vehicle: the mobile laboratory is based on a regular Ford Transit FT350-L delivery vehicle with long wheelbase and high roof (length: $5.7 \mathrm{~m}$, width: $1.97 \mathrm{~m}$, total height: $3.15 \mathrm{~m}$ ). The gross vehicle weight has been increased from $3.5 \mathrm{t}$ to $3.85 \mathrm{t}$ to supply sufficient payload capacity for the installations and instruments. The driver compartment accommodates a single driver and a dual passenger seat. It is separated from the payload/instrument compartment by a fullsteel bulkhead outfitted with a sliding window. In the instrument compartment the vehicle was retrofitted with an operator's seat (JANY 862, Jany A/S, Denmark) which is approved for use during driving. The operator's seat is located next to the glazed sliding load door. To minimize shock impacts onto the instruments while driving the rear wheels are equipped with air suspension that also keeps the vehicle at a constant drive height independent of the payload weight. For further shock reduction individual instruments are equipped with shock-absorbing devices.

Power and heat management: the vehicle is equipped with a 2.4-1 TDCi engine providing $103 \mathrm{~kW}(140 \mathrm{hp})$ power and rear wheel drive. With a coated Diesel Particulate Filter (cDPF) that removes most of the particles from the exhaust and minimizes self-contamination when the engine is running the vehicle meets emission standards below the Euro V requirements.

The electrical power supply in the mobile laboratory is designed to continuously provide electricity to the instruments under various operational conditions without being susceptible to faulty operation by the user. For this purpose an intelligent power management is used to select the best available source of power at any time (Fig. 1). When the vehicle engine is running, two $4.5 \mathrm{~kW}$-alternators installed under the engine hood and directly connected to the engine generate 3-phase $250 \mathrm{VAC}$ power with a frequency depending on the engine speed. After rectification $230 \mathrm{~V} 50 \mathrm{~Hz}$ AC power is generated in two inverter modules (MB5000, MobiE, Germany). The electricity from the two power generators feeds three circuits in the mobile laboratory. Alternatively, these circuits can be powered externally either by a single 3-phase $400 \mathrm{VAC}$ power line or by three individual regular $230 \mathrm{VAC}$ lines. The latter option is especially useful if power is required at less well equipped locations like at a 


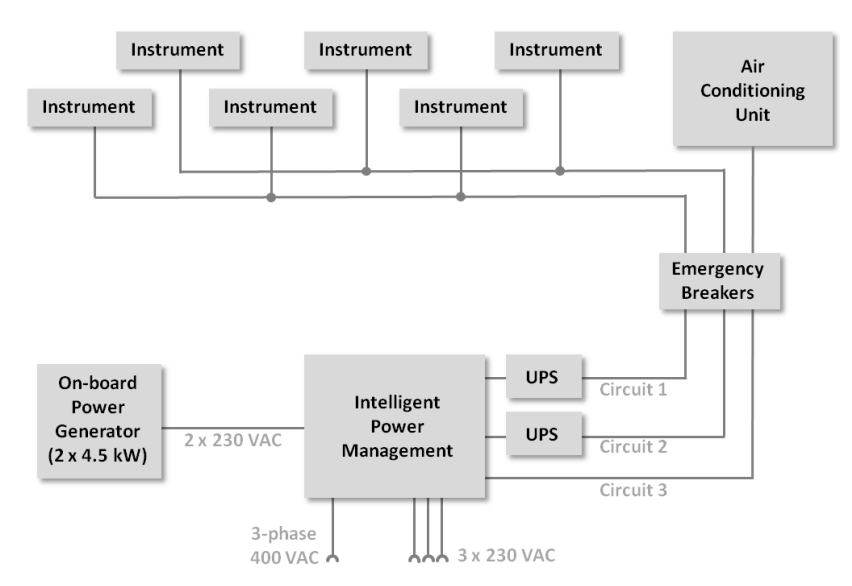

Fig. 1. Schematics of the electrical circuitry in the mobile laboratory. Intelligent power management selects the preferred power supply (on-board generated power, three individual 230 VAC lines or 3-phase $400 \mathrm{VAC}$ ) to feed the three power circuits on board. The two instrument circuits are buffered by uninterruptable power supplies (UPS).

hotel for overnight powering of the mobile laboratory. Two of the three circuits are used for the measurement instrumentation in the vehicle. They are each buffered with an UPS system (APC SmartUPS RT 6000), that allows uninterrupted operation of all instruments for a minimum of $30 \mathrm{~min}$ without external or on-board power. The third circuit is used to power the air conditioning unit without UPS buffering (Fig. 1). For all three circuits wall-mounted sockets are distributed in the instrument compartment, outfitted with circuit breakers and ground-fault breakers. Additional sockets are located in the driver compartment. Emergency breakers are located in both compartments near the operator seats.

The heat generated by the instruments and introduced from outside is removed using an air conditioning (AC) unit (Carrier AC8-S, Carrier Sütrak, Germany) installed on the roof above the front part of the instrument compartment. It has a cooling capacity of $9.4 \mathrm{~kW}\left(32000 \mathrm{BTU} \mathrm{h}^{-1}\right)$ with a turnover rate of up to $1500 \mathrm{~m}^{3} \mathrm{~h}^{-1}$. The AC unit is completely powered by 230 VAC allowing its operation with on-board as well as external electrical power. To minimize the heat influx from the environment the side walls and the roof are insulated with approximately $3 \mathrm{~cm}$ thick foam material and $3 \mathrm{~mm}$ plywood covered with a washable surface. On the floor $18 \mathrm{~mm}$ plywood covered with a non-skid waterproof finish provides both, thermal insulation and a safe low-maintenance lining. In addition the external pumps of the instruments are located in an insulated box in the back of the vehicle, equipped with a blower that directly removes their heat from the vehicle together with the hot exhaust air from the built-in air conditioning unit of the AirPointer (see below).

Data management: a local area network (LAN) connects data acquisition computers and instruments (see below) and allows the connection of data acquisition computers for additional instruments or of laptops. For this purpose several LAN sockets (RJ45) are mounted in the instrument compartment and the driver compartment of the vehicle and are connected to a central 8-port LAN-switch (GS108, Netgear). A router (Vigor 2910, DrayTek) is used to connect the mobile laboratory network to the internet either using a $3 \mathrm{G}$ internet stick with an external antenna or a cable connection to an existing network.

Occupational safety: several features have been installed in the mobile laboratory for safety reasons. Six flood lamps on the roof of the vehicle can be used to illuminate the working environment around the vehicle when operating at night in remote environments. Amber lights at the front and the rear of the roof as well as foldable traffic cones can be used to secure busy work environments. In case of an emergency two $\mathrm{CO}_{2}$ fire extinguishers as well as an extended first aid kit including AED (automatic external defibrillation) are available.

\subsection{The inlet system for aerosol and gas sampling}

During the development phase of the mobile laboratory, a special focus was the design of the aerosol inlet and transport system to assure best possible aerosol measurement efficiency with well-known losses for the different operational modes of the platform. The aim was to develop a common inlet system for all aerosol instruments in the vehicle that is not only optimized for transport losses, but is also well suited for stationary as well as mobile measurements with little conversion effort needed to switch between both setups.

Estimation of sampling losses: the first step was the development of a software tool to calculate sampling and transport efficiencies through user-defined tube systems on the basis of parameterizations from the existing literature and validated with measurements for simple tube geometries. This tool, the Particle Loss Calculator (PLC, von der Weiden et al., 2009), allows the definition of complex inlet systems based on simple geometries and the calculation of size-dependent particle transmission efficiencies or transport losses taking into account all relevant deposition mechanisms.

Within the boundary conditions set by the vehicle dimensions and the approximate total aerosol inlet flow rate of all instruments transport loss calculations were performed for different realisations of the various aspects of the inlet system. These calculations showed that for the given total inlet flow rate of approximately $901 \mathrm{~min}^{-1}$ a single transport tube in the vehicle with an inner diameter of $66 \mathrm{~mm}$ is superior compared to a single tube of other diameters and over multiple tubes in parallel that have the same combined diameter (Fig. 2a). A tube of smaller diameter would provide lower losses for large particles, however, with the disadvantage that the aerosol flow would be outside the laminar flow regime with increased losses of small particles due to eddy diffusion. Other calculations have shown that efforts like reducing impaction losses in bends by enlarging the tube diameter 

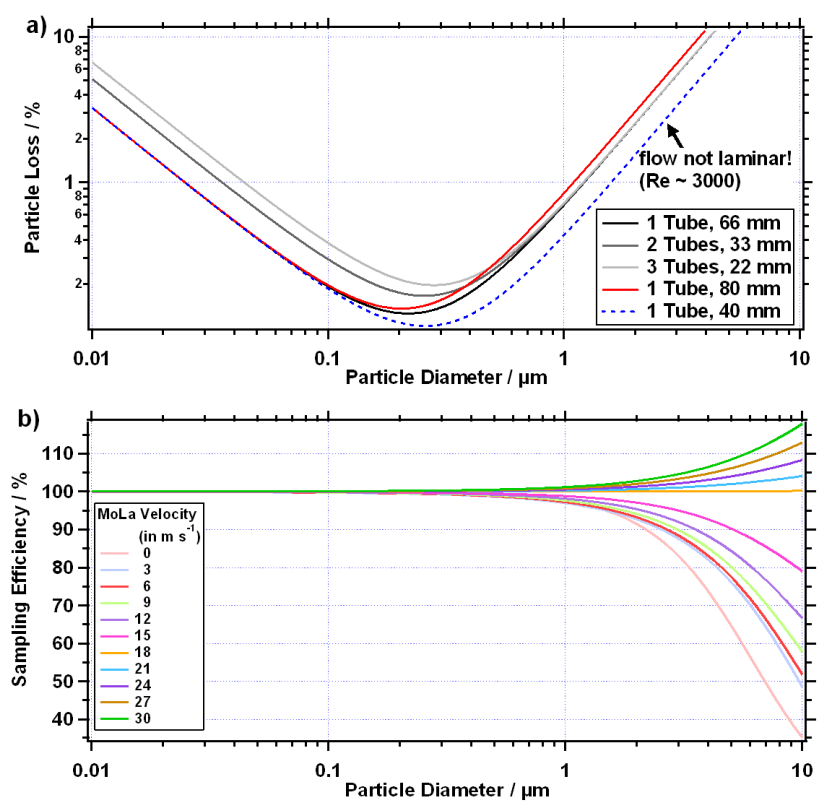

Fig. 2. (a) Transport losses in the main inlet tube as a function of particle size. Based on these calculations the $66 \mathrm{~mm}$ ID tube was selected for MoLa. Multiple tubes of smaller diameter result in larger losses of small particles. A single larger tube shows more losses for large particles and for the narrow tube ( $40 \mathrm{~mm}$ ID) the flow is outside the laminar regime. (b) Sampling efficiency as a function of particle size for different driving velocities and isoaxial sampling (upper front inlet).

before the bend or running the tube diagonally through the vehicle instead of locating it along the walls do not provide significant improvements in transport efficiency.

Layout of the internal aerosol flow system: as a consequence of these transport loss calculations the common aerosol inlet system was installed (Fig. 3) in the mobile laboratory. It consists of a main stainless steel inlet tube of $66 \mathrm{~mm}$ inner diameter that is running from the upper front of the instrument compartment along the wall to the back of the vehicle where it crosses the compartment perpendicularly just below the roof (von der Weiden, 2008). From this main tube the aerosol flows for the individual instruments are branched off at a point of the main tube near the instruments to their inlet using $1^{\prime \prime}, 1 / 2^{\prime \prime}$ or $1 / 4^{\prime \prime}$ stainless steel tubes depending on the individual inlet flows of the instruments. At the end of the main inlet tube a makeup-flow is extracted to fill the gap between the total instrument flow rate and the desired flow rate of the inlet system (typically $901 \mathrm{~min}^{-1}$ ). This makeupflow is monitored with a thermal mass flow meter (Model 4043, TSI, Inc.) and controlled with an adjustable critical orifice and a scroll pump (SH-100, Varian, Inc.). The location of the individual instruments within the instrument compartment and relative to the main inlet tube was selected such that the effect of transport losses on measured aerosol parameters is at a minimum for all sampling inlets (see below).

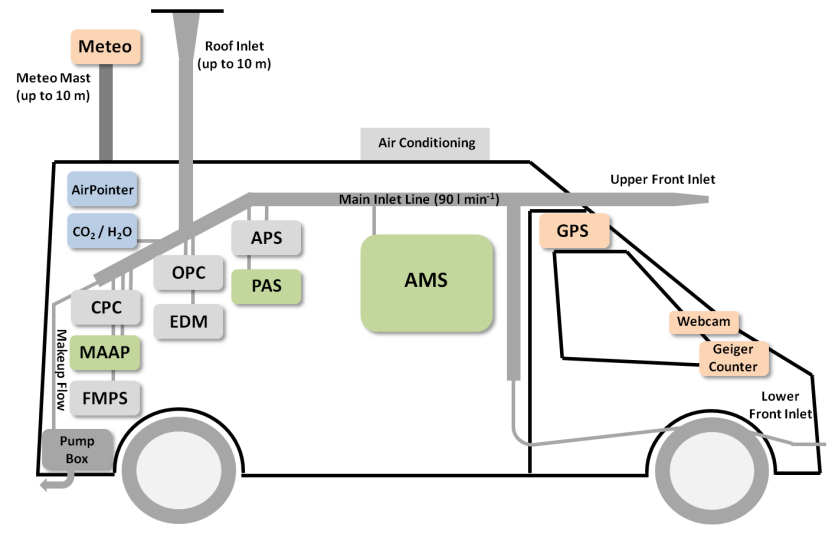

Fig. 3. Schematic overview of the MoLa aerosol inlet system and of the locations of the various instruments within the vehicle (grey: instruments for physical aerosol parameters; green: instruments for aerosol composition; blue: gas-phase instruments; red: other instruments).

This means that for example, particle number concentration measurements, which are dominated by the smallest particles, require a sampling tube optimized for small diffusional losses while no special focus has to be laid on transport losses by inertial impaction and sedimentation, which affect mainly larger particles. For instruments that measure parameters strongly affected by the concentration of large particles, the inlet line was optimized for minimal sedimentation and impaction losses, while the reduction of diffusional losses did not have first priority. As a consequence of such optimization processes instruments for coarse particle size distribution and $\mathrm{PM}_{10}$ measurements are located directly below the (stationary) sampling inlet with no significant horizontal parts or bends in the tube.

Design of the multi-inlet sampling system: the mobile laboratory is equipped with three aerosol sampling inlets (Fig. 3). Two inlets for mobile measurements are located at the front of the vehicle and one inlet for stationary measurements on the roof. For car-chasing experiments, where the aerosol is sampled approximately at tailpipe height, or for other near-ground measurements a sampling inlet in the front bumper of the vehicle is installed. Due to technical limitations this inlet consists of four collinear $1 / 2^{\prime \prime}$ stainless steel tubes that are routed below the vehicle engine and merged inside the instrument compartment into the main inlet tube. For all other types of mobile measurements (see below), the upper front inlet is used. It is designed as an extension of the main inlet tube that extends $75 \mathrm{~cm}$ out of the vehicle contour above the driver seat at a height of $2.20 \mathrm{~m}$ above street level. At its front end it is equipped with an exchangeable sampling cone. The sampling cone typically used for mobile measurements has a sampling diameter of $10 \mathrm{~mm}$ for isokinetic sampling at a vehicle speed of $65 \mathrm{~km} \mathrm{~h}^{-1}$. Particle Loss Calculator estimates for the sampling efficiency of the sampling 
cone as a function of particle diameter for various MoLa driving velocities are shown in Fig. 2b. As shown by von der Weiden (2008), non-isokinetic sampling does not have significant effects on the measurements for particle sizes below several micrometers, even if the vehicle drives at a velocity very different from isokinetic speed.

The third sampling inlet used for stationary measurements is located in the middle of the vehicle's roof directly above the main instrument rack. The vertical transport line from the sampling head down to the vehicle is made of a variable number of one- and two-metre long straight aluminum tube sections with an outer diameter (OD) of $50 \mathrm{~mm}$ that are joined by o-ring sealed self-supporting connectors for rapid assembly. This tube system can be extended up to $6 \mathrm{~m}$ above ground level without any support and up to $10 \mathrm{~m}$ height with supporting ropes. On top of this tube system a sampling inlet head is attached to these connectors. The sampling head is a non-discriminating total suspended particle (TSP) head that prevents rain and insects from being introduced into the sampling line. For mobile measurements the roof inlet is closed using an o-ring sealed cap on the inlet tube, for stationary measurements the front inlets are closed using in-line valves at the front end of the aerosol tube. An overview over the transport losses for the individual instruments is given in Fig. 4 for the upper front and the roof inlet.

Gas sampling: gas phase species are sampled through 1/4" Teflon tubing that is placed alongside the main aerosol lines. For the upper front inlet a Teflon line is permanently installed reaching to the front end of the inlet cone. For the roof inlet a Teflon line is installed together with the aerosol sampling line alongside the aluminum tube when the tube is mounted. This line can be quickly connected to the instruments using a single Ultratorr fitting on the roof. A three-way valve in the vehicle is used to switch the gas phase instruments to either the front or the roof inlet.

\section{Instrumentation}

\subsection{Aerosol physical and chemical measurements}

The major focus of the mobile laboratory is the investigation of the ambient aerosol. The related instruments were chosen to provide a combination of in-depth aerosol information with time resolution in the lower second range as far as possible. Physical aerosol parameters that are measured include particle number concentration of particles larger $2.5 \mathrm{~nm}$ diameter and particle mass concentrations for the $\mathrm{PM}_{1}, \mathrm{PM}_{2.5}$, and $\mathrm{PM}_{10}$ size fractions. Particle size distributions are measured with three instruments and cover the particle diameter range from about $6 \mathrm{~nm}$ up to more than $30 \mu \mathrm{m}$ : the electrical mobility diameter is measured for the smallest particle size range, while with some overlap the coarser particles are measured using an optical particle spectrometer and aerodynamic particle sizer.

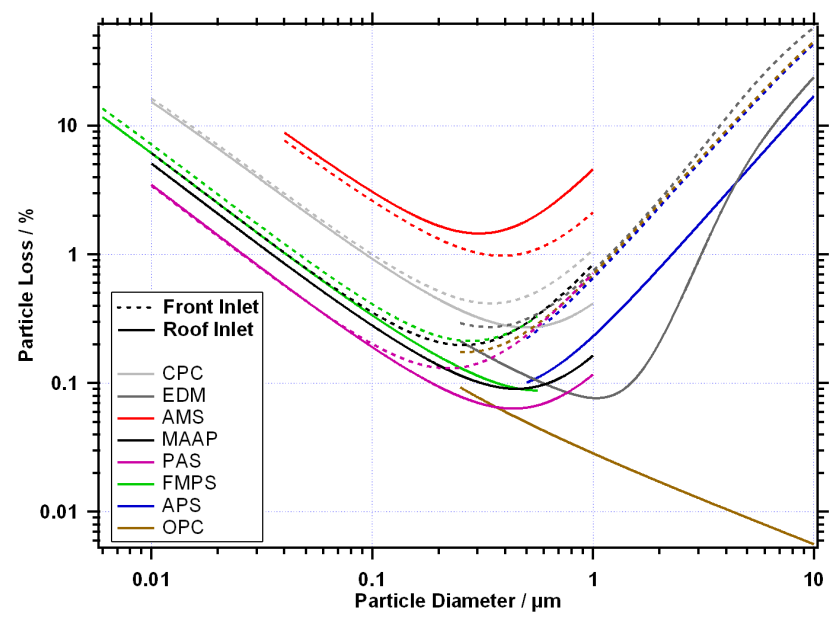

Fig. 4. Overview of inlet transport losses as a function of particle diameter for all aerosol instruments in MoLa. The solid lines represent the loss calculations for the roof inlet and for $6 \mathrm{~m}$ sampling height; the dashed lines represent the calculations for the upper front inlet.

Information about the chemical composition of the particles is gathered for the submicron particle size range only. The non-refractory aerosol composition is measured using a thermal desorption aerosol mass spectrometer (Aerodyne ToF-AMS; Drewnick et al., 2005; DeCarlo et al., 2006) that provides information about the mass concentration of sulfate, nitrate, ammonium, chloride and total organic material as well as species-resolved mass distributions. Together with black carbon concentration measurements using optical transmission most of the sub-micron aerosol components are determined. Finally total particulate surface PAH concentrations are measured using a photo-ionization technique. In addition, prearrangements for the installation of a laser ablation single particle aerosol mass spectrometer, either SPLAT-5 or ALABAMA (Kamphus et al., 2008 or Brands et al., 2011), into the mobile laboratory have been made. Extra space and sampling ports at the main inlet line are available to accommodate additional "guest" instruments from partners for specialised measurements during common individual projects or for future extensions of the measurement capabilities of the vehicle. An overview of the positions of the individual instruments within the vehicle is provided in Fig. 3.

Detailed information about the instrument types, measured particle size ranges, flow rates, measurement time resolution and detection limits of all these instruments is provided in Table 1 . In addition, for each instrument, the particle transport losses in the inlet line are specified in Table 1 for the smallest and largest measured particle diameter, calculated for the roof inlet with $6 \mathrm{~m}$ sampling height. As shown in Fig. 4, transport losses are generally smaller for intermediate diameters, resulting in under-measurements of the individual integrated particle characteristics that are below the extreme values provided in Table 1 and are typically a few percent 
only. When sampling through the front inlet particle losses are slightly larger for most of the instruments due to the long horizontal distance that the particles have to be transported to the instruments. However, also for this inlet losses are also typically below a few percent.

For highly time-resolved measurements with multiple instruments it is crucial to synchronise data acquisition (see below), as well as to associate the actual measurement times with the exact time when the aerosol was sampled into the inlet system. The residence times of the aerosol in the inlet system of MoLa was calculated for each instrument. Comparison of these times with measured residence times show good agreement within an uncertainty in the order of $\pm 2 \mathrm{~s}$. The resulting delay times for the front and the roof inlets are also shown in Table 1. They are used to correct the measurement time in order to obtain the exact sampling time for the respective parameter.

\subsection{Trace gas monitoring and meteorological parameters}

For basic information about the most important trace gases monitoring-grade gas analysers are installed in MoLa. An AirPointer (Recordum Messtechnik GmbH, Austria), a fourin-one setup, that is housed in a common air-conditioned enclosure, measures nitrogen oxides, carbon monoxide, sulfur dioxide and ozone. While 4-s data are collected from the instrument the internal measurement time constants of the individual sensors are partially longer, resulting in real time resolutions between four and $20 \mathrm{~s}$. Additionally, a nondispersive infrared gas analyser provides one-second carbon dioxide and water vapour concentrations.

Meteorological data are collected with a compact weather station (WXT520, Vaisala, Finland) and an additional pyranometer that are both installed on top of an extendable mast (SQT 9/HP, Clark Masts, UK). During driving the station is located about $0.5 \mathrm{~m}$ above the roof. For stationary measurements the mast can be extended pneumatically using a hand pump to measure the meteorological parameters at a height of up to $10 \mathrm{~m}$ above ground level. Wind speed and direction are measured with an ultrasonic 2-D-anemometer. These parameters as well as ambient temperature, relative humidity, ambient pressure, precipitation and global solar radiation are measured with one second time resolution.

A Geiger counter installed in the driver's compartment is used to measure radioactivity with a time resolution of $10 \mathrm{~s}$. A webcam is also installed there just behind the windshield and pointing forward to record the co-driver's view while driving or during stationary measurements. During data processing these videos can be very helpful in identifying and explaining unusual events in the data that are not explained by manual notes in the laboratory notebook or to separate contaminated and uncontaminated data (see below). Finally, the vehicle is equipped with a GPS navigation system that continuously provides vehicle location and speed, recorded by the data acquisition computer. An overview over the nonaerosol measurement instruments and details of the measurements are provided in Table 2.

\section{Data acquisition}

To minimize the time and labour for data analysis and to obtain a direct real-time overview of the measured parameters a dedicated data acquisition and display system was developed for the mobile laboratory. All data measured by the standard MoLa instrumentation are collected by one central data acquisition computer. The only exception is the aerosol mass spectrometer that has its own computer to handle the large amount of primary data which has to be pre-processed and saved directly. For instrument control the operator in the instrument compartment has a $20^{\prime \prime}$ computer monitor that is mounted to the bulkhead in front of the operator seat and a retractable keyboard. Both devices are connected to the central data acquisition computer and the aerosol mass spectrometer computer via an electronic switch that allows the alternate control of both computers over a single interface.

Most instruments are connected to the data acquisition computer via a serial (RS232) port. To be able to gather the data from all instruments simultaneously the computer is equipped with two RS232 ports and an 8-port RS232 PCIcard (Lava Octopus 550 8-Port PCI Serial Port, Lava Computer MFG, Inc.). Additionally up to four USB-RS232 converters can be connected, resulting in a total of 14 serial ports. The remaining instruments are connected directly via USB.

The MoLa data acquisition and live display system itself consists of two independent tools that run in parallel on separate IGOR Pro (Wavemetrics, Inc., USA) platforms on the data acquisition computer.

The data acquisition tool collects and saves the measurement data from all instruments with a high time resolution. For this purpose the software communicates with the individual instruments using the VISA (Virtual Instrument Software Architecture, National Instruments Corp., USA) interface. The instruments are set to an automatic mode where they send measurement and housekeeping data in defined time intervals as plain text, either by a command from the software tool or manually. For each instrument the software performs continuously a loop that includes four steps: (1) check whether the instrument has sent data; (2) if so, read these, else wait for next iteration; (3) parse the data to extract predefined information; (4) save the data and wait for next iteration. The data of the AirPointer are retrieved by using the instrument's ability to show its measurement values as a simple webpage in $\mathrm{html}$ format. This webpage is read by the IGOR tool and the data are automatically extracted.

Typically the time between two executions of the data collection loops is $500 \mathrm{~ms}$ while the time to finish each execution is below $20 \mathrm{~ms}$. All collected data are then written into a separate FiFo (first in first out) file for each instrument, 
Table 1. Summary of aerosol measurement instruments in MoLa. The losses in the inlet line are provided for the smallest and largest measured particle diameter of the instrument for the roof inlet. The sampling delay (upper front \& roof inlet) is the aerosol residence time in the inlet system.

\begin{tabular}{|c|c|c|c|c|c|c|}
\hline $\begin{array}{l}\text { Measurement } \\
\text { Instrument }\end{array}$ & Measured Quantity & $\begin{array}{l}\text { Size Range } \\
\text { (Particle losses) }\end{array}$ & Flow Rate & $\begin{array}{l}\text { Sampling } \\
\text { Delay }\end{array}$ & Time Resolution & Lower Detection Limit ${ }^{\mathrm{a}}$ \\
\hline $\mathrm{AMS}^{\mathrm{b}}$ & $\begin{array}{l}\text { Size-resolved aerosol } \\
\text { chemical composition }\end{array}$ & $\begin{array}{l}40 \mathrm{~nm}(9 \%)- \\
600 \mathrm{~nm}(2 \%) d_{\mathrm{va}}\end{array}$ & $0.11 \mathrm{~min}^{-1}$ & $9 / 51 \mathrm{~s}$ & Typ. $30 \mathrm{~s}-1 \mathrm{~min}$ & $\begin{array}{l}\mathrm{SO}_{4}: 0.04 \mu \mathrm{g} \mathrm{m}^{-3} \\
\mathrm{NO}_{3}: 0.02 \mu \mathrm{g} \mathrm{m}^{-3} \\
\mathrm{NH}_{4}: 0.05 \mu \mathrm{g} \mathrm{m}^{-3} \\
\text { Org: } 0.09 \mu \mathrm{g} \mathrm{m}^{-3}\end{array}$ \\
\hline MAAP $^{c}$ & $\begin{array}{l}\text { Black carbon mass } \\
\text { concentration }\end{array}$ & $\begin{array}{l}10 \mathrm{~nm}(5 \%)- \\
1 \mu \mathrm{m}(0.2 \%)\end{array}$ & $16.671 \mathrm{~min}^{-1}$ & $11 / 6 \mathrm{~s}$ & $1 \mathrm{~min}$ & $0.1 \mu \mathrm{g} \mathrm{m}^{-3}$ \\
\hline $\mathrm{PAS}^{\mathrm{d}}$ & $\begin{array}{l}\text { Total surface PAH mass } \\
\text { concentration }\end{array}$ & $\begin{array}{l}10 \mathrm{~nm}(4 \%)- \\
1 \mu \mathrm{m}(0.2 \%)\end{array}$ & $21 \min ^{-1}$ & $12 / 6 \mathrm{~s}$ & $12 \mathrm{~s}$ & $1 \mathrm{ng} \mathrm{m}^{-3}$ \\
\hline $\mathrm{EDM}^{\mathrm{e}}$ & $\begin{array}{l}\mathrm{PM}_{1}, \mathrm{PM}_{2.5}, \mathrm{PM}_{10} \text { based on } \\
\text { optical size distribution } \\
\text { measurement }(0.25-32 \mu \mathrm{m})\end{array}$ & $\begin{array}{l}0.25 \mu \mathrm{m}(0.2 \%)- \\
10 \mu \mathrm{m}(24 \%)\end{array}$ & $1.21 \mathrm{~min}^{-1}$ & $10 / 5 \mathrm{~s}$ & $6 s$ & $\begin{array}{l}\text { Range: } 0.1-1500 \mu \mathrm{g} \mathrm{m}^{-3} \\
\text { Reproducibility: } 5 \%\end{array}$ \\
\hline $\mathrm{CPC}^{\mathrm{f}}$ & $\begin{array}{l}\text { Particle number } \\
\text { concentration }\end{array}$ & $\begin{array}{l}2.5 \mathrm{~nm}(15 \%)- \\
1 \mu \mathrm{m}(0.4 \%)\end{array}$ & $0.61 \min ^{-1}$ & $11 / 6 \mathrm{~s}$ & $1 \mathrm{~s}$ & N/A \\
\hline FMPSg & $\begin{array}{l}\text { Particle size distribution } \\
\text { based on electrical mobility }\end{array}$ & $\begin{array}{l}5.6 \mathrm{~nm}(12 \%)- \\
560 \mathrm{~nm}(0.1 \%)\end{array}$ & $101 \min ^{-1}$ & $11 / 6 \mathrm{~s}$ & $1 \mathrm{~s}$ & N/A \\
\hline APS $^{h}$ & $\begin{array}{l}\text { Particle size distribution } \\
\text { based on aerodynamic sizing }\end{array}$ & $\begin{array}{l}0.5 \mu \mathrm{m}(0.1 \%)- \\
20 \mu \mathrm{m}(58 \%)\end{array}$ & $51 \min ^{-1}$ & $10 / 8 \mathrm{~s}$ & $1 \mathrm{~s}$ & N/A \\
\hline $\mathrm{OPC}^{\mathrm{i}}$ & $\begin{array}{l}\text { Particle size distribution } \\
\text { based on light scattering }\end{array}$ & $\begin{array}{l}0.25 \mu \mathrm{m}(0.1 \%)- \\
32 \mu \mathrm{m}(<0.1 \%)\end{array}$ & $1.21 \mathrm{~min}^{-1}$ & $10 / 5 \mathrm{~s}$ & $6 s$ & N/A \\
\hline
\end{tabular}

${ }^{a}$ Determined using the method described in Drewnick et al. (2009). ${ }^{b}$ HR-ToF-AMS, Aerosol Mass Spectrometer, Aerodyne Res., Inc., USA. ${ }^{c}$ Multi-Angle Absorption Photometer, Thermo Electron Corp., USA. ${ }^{\mathrm{d}}$ PolyAromatic hydrocarbon Sensor PAS2000, Ansyco, Germany. ${ }^{\mathrm{e}}$ Environmental Dust Monitor EDM180, Grimm Aerosoltechnik, Germany. ${ }^{\mathrm{f}}$ Condensation Particle Counter Model 3786, TSI, Inc., USA. ${ }^{\mathrm{g}}$ Fast Mobility Particle Sizer Spectrometer Model 3091, TSI, Inc., USA.

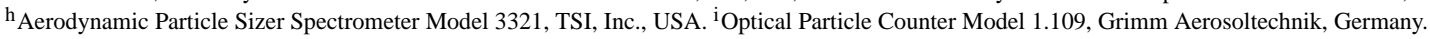

which is a binary file with pre-defined format, located in a user-selected folder of the data acquisition computer. The user interface for the data acquisition tool was kept as simple as possible to avoid accidental operating errors.

The data live display tool is not involved in the data acquisition itself. It only displays all data collected by the data acquisition tool in real time and in a well-arranged way to provide the overview over all measurements for the instrument operator (Fig. 5). In addition to graphs that contain time series of all parameters the user can select whether the last measured value or an average over a defined time interval is displayed as plain number for each of the parameters. A graph control panel allows the user to select the displayed ranges for each of the data displays as well as to select the time interval that is shown (e.g., only the last $10 \mathrm{~min}$ ). Overview graphs for aerosol concentrations or spatial distribution of parameters along the vehicle track can easily be generated by pushing a control key. The logbook manager supports the operator in keeping a log of all events. Logbook entries are automatically saved with the exact logging times. Event markers can be used to generate predefined logbook entries with a single button click.

Compared to measurements with the individual software packages that came with the instruments the unified data collection implemented in MoLa has the advantage to provide a direct overview over all measured data, allowing for a potentially necessary adaption of the measurement strategy. Also, all data are saved with a common time base in a common format. The original software provided with the instruments typically has a special data format that is different for each manufacturer and instrument. In addition, the overview of all measurements is hard to obtain with multiple windows, each showing a single parameter, often together with multiple housekeeping data.

The time base of all measurements is the data acquisition computer time which is frequently synchronised with the GPS system on-board the mobile laboratory (usually once per day). Additional synchronization between the time base of the aerosol mass spectrometer computer and that of the data acquisition computer provides a common time base for all instruments within MoLa with sub-second accuracy. All in all, the common data acquisition software allows the generation of quick-looks for a first overview of a large fraction of the atmospheric situation within minutes after the end of a measurement, even though approximately 40 different parameters were measured with 14 instruments. However, thorough analysis and quality assurance of the data is a time-consuming task that takes weeks or months depending on the length and complexity of the measurement application. 
Table 2. Summary of non-aerosol measurement instruments in the mobile laboratory MoLa with various instrument details. The sampling delay is the time the measurement is performed after the actual occurrence of the ambient feature, calculated for the roof inlet with $6 \mathrm{~m}$ sampling height.

\begin{tabular}{|c|c|c|c|c|c|}
\hline $\begin{array}{l}\text { Measurement } \\
\text { Instrument }\end{array}$ & Measured Quantity & Flow Rate & $\begin{array}{l}\text { Sampling } \\
\text { Delay }\end{array}$ & Time Resolution & Lower Detection Limit \\
\hline AirPointer ${ }^{\mathrm{a}}$ & $\begin{array}{l}\mathrm{O}_{3}, \mathrm{SO}_{2}, \mathrm{CO}, \mathrm{NO}, \mathrm{NO}_{2} \\
\text { mixing ratio }\end{array}$ & $31 \min ^{-1}$ & $2 \mathrm{~s}$ & $4 \mathrm{~s}$ & $\begin{array}{l}\mathrm{O}_{3}:<1.0 \mathrm{ppbv} \\
\mathrm{SO}_{2}:<1.0 \mathrm{ppbv} \\
\mathrm{CO}:<0.2 \mathrm{ppmv} \\
\mathrm{NO}_{\mathrm{X}}:<1.0 \mathrm{ppbv}\end{array}$ \\
\hline $\mathrm{LICOR}^{\mathrm{b}}$ & $\mathrm{CO}_{2}$ and $\mathrm{H}_{2} \mathrm{O}$ mixing ratio & $11 \min ^{-1}$ & $6 s$ & $1 \mathrm{~s}$ & $\begin{array}{l}\mathrm{CO}_{2}: 1 \mu \mathrm{mol} \mathrm{mol}^{-1} \text { (RMS noise) } \\
\mathrm{H}_{2} \mathrm{O}: 0.01 \mathrm{pmol} \mathrm{mol}^{-1} \text { (noise) }\end{array}$ \\
\hline Met. Station ${ }^{c}$ & $\begin{array}{l}\text { Wind speed, wind direction, } \\
\text { temperature, relative } \\
\text { humidity, rain intensity, } \\
\text { pressure }\end{array}$ & N/A & $0 \mathrm{~s}$ & $1 \mathrm{~s}$ & $\begin{array}{l}\text { Accuracy: } \\
\text { WSp: } 0.3 \mathrm{~m} \mathrm{~s}^{-1} ; \mathrm{Wdir}: 3^{\circ} \\
T: 0.3^{\circ} \mathrm{C} ; \mathrm{RH}: 3 \% \\
\text { Rain: } 5 \% ; P: 0.5 \mathrm{hPa}\end{array}$ \\
\hline Pyranometer $^{d}$ & Solar radiation intensity & N/A & $0 \mathrm{~s}$ & $1 \mathrm{~s}$ & $10 \%$ (total uncertainty) \\
\hline Geiger Counter ${ }^{\mathrm{e}}$ & $\alpha, \beta, \gamma$ radiation & N/A & $0 \mathrm{~s}$ & $10 \mathrm{~s}$ & N/A \\
\hline GPS $^{f}$ & Vehicle location and speed & N/A & $0 \mathrm{~s}$ & $1 \mathrm{~s}$ & N/A \\
\hline Webcam ${ }^{\mathrm{g}}$ & $\begin{array}{l}\text { Co-driver's view through } \\
\text { windshield }\end{array}$ & N/A & $0 \mathrm{~s}$ & $1 \mathrm{~s}$ & N/A \\
\hline
\end{tabular}

${ }^{a}$ AirPointer, Recordum Messtechnik GmbH, Austria. ${ }^{b}$ LI840, Licor, USA. ${ }^{c}$ WXT520, Vaisala, Finland. ${ }^{d}$ CMP3, Campbell Scientific, Inc., UK. ${ }^{e}$ Gamma-Scout online,

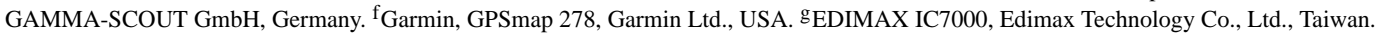

\section{Measurement applications}

The mobile laboratory was designed for two fundamentally different measurement approaches: stationary measurements and mobile measurements while driving. Both types of measurements allow a broad variety of applications to address various scientific questions, which often cannot or are much harder to be addressed using "classical" approaches.

\subsection{Operating MoLa as a measurement station}

In general, stationary measurements can be performed using a normal laboratory container located at the desired sampling site, equipped with the instrumentation needed for the actual scientific objective. For regular field measurement campaigns, where ambient air is probed over several weeks at one location (e.g., Diesch et al., 2011), the mobile laboratory has the advantage of a well-known and well-characterised instrumental setup designed for minimal losses and sampling artifacts, resulting in better-defined measurements than often achieved in field setups.

The biggest advantages compared with classical field measurements are achieved when measurements have to be performed at multiple locations or when the sampling sites are not identified well ahead of time (e.g., Schneider et al., 2008). Especially when individual emission sources are probed, like for example road traffic, ships, forest fires or industrial facilities, the sampling location strongly depends on the actual wind direction and often has to be identified spontaneously based on current weather conditions. Additionally, sampling of the same emissions at different distances or probing of various sources demands multiple changes of the sampling location within very short times. Typically, in all these cases no preparations for the individual sampling points can be made, resulting in the lack of logistical support as, for example, the supply of electrical power.

The design of the mobile laboratory allows stationary measurements under well-defined conditions with high efficiency. The inlet system for stationary sampling several metres above road level is installed only within a few minutes. For the supply with electrical power during stationary measurements at arbitrary locations two different approaches have been developed. An external $15 \mathrm{~kW}$ gasoline power generator on a separate vehicle can be parked up to $100 \mathrm{~m}$ downwind of the mobile laboratory to power the instruments via a long power cord along the ground. An even more flexible method associated with much less effort and costs is the active exhaust removal system of the mobile laboratory (Fig. 6). A blower is installed at the end of a $25 \mathrm{~m}$ long flexible $100 \mathrm{~mm}$ ID hose, which is imposed on the tailpipe of the mobile laboratory. The blower draws approximately $10001 \mathrm{~min}^{-1}$ of air through the hose, and the exhaust gas is immediately diluted at the tailpipe by additional ambient air. The diluted exhaust of the mobile laboratory is released to ambient about $25 \mathrm{~m}$ downwind of the vehicle. Tests 


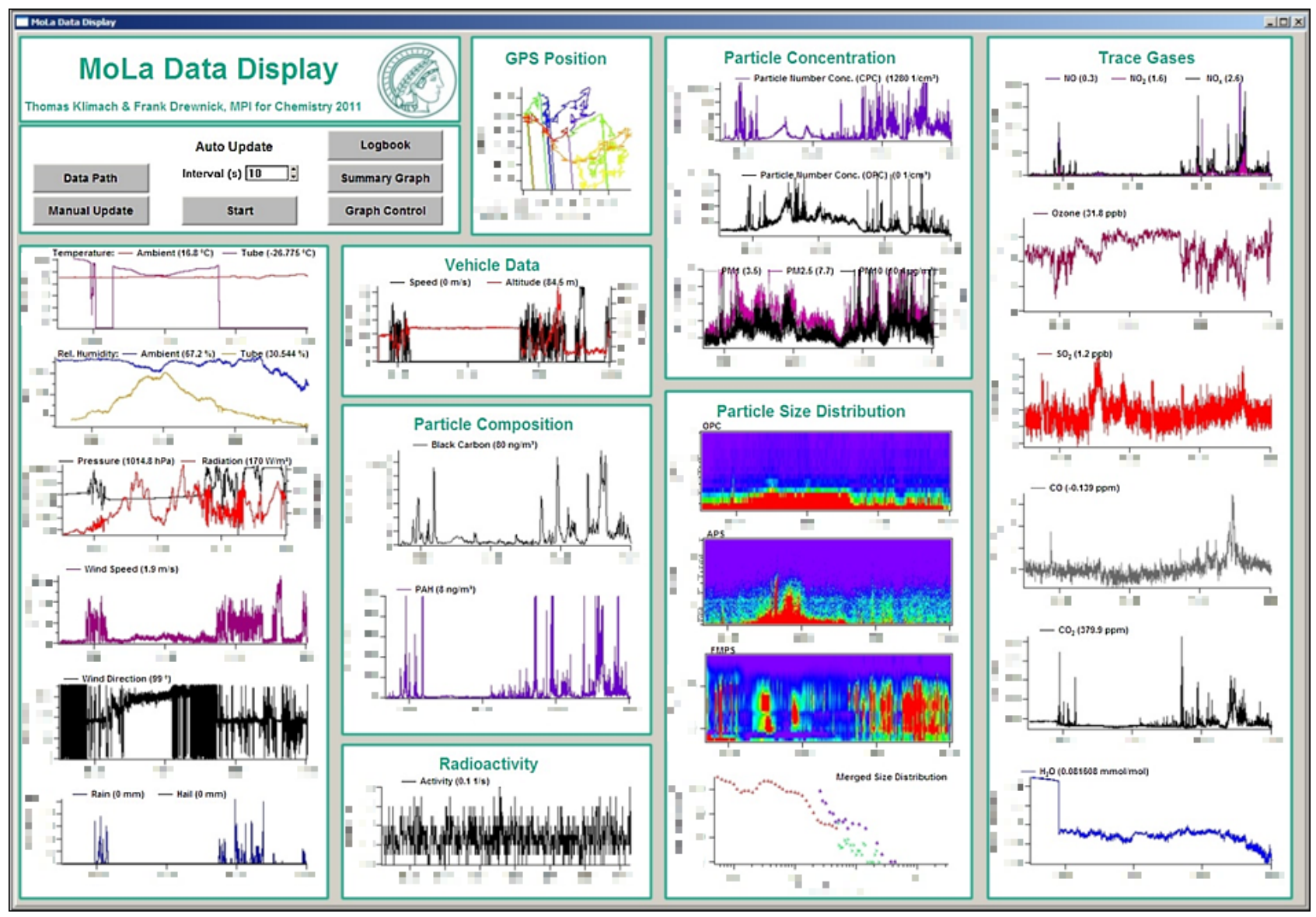

Fig. 5. Data live display tool of the mobile laboratory showing time series and current measurement data of all parameters (except AMS data and webcam image) on a single screen. Graph control, summary graphs and logbook functions are activated by buttons on the top left.

have shown that this procedure results in negligible emissionrelated concentrations as close as about $5 \mathrm{~m}$ upwind of the release point, even under unfavourable conditions, e.g., with low wind speeds.

This configuration allows very quick installation of all necessary facilities for stationary measurements. With a crew of two operators the whole setup can be finished within less than ten minutes upon arrival at an arbitrary sampling site and the stationary measurement can be started. Thus, it is possible to perform several point measurements at different locations on a single day. An example of such an application is shown in Fig. 7. Here ambient air measurements were performed downtown of Mainz, Germany (200000 inhabitants) and at a background location $10 \mathrm{~km}$ upwind of the city on the same day during a student's exercise in April 2011. Data were recorded continuously also while driving between the two stationary measurements, which are indicated by the shaded areas (grey for "city" and green for "background").

The time series of the various air pollutants in the left panel show not only significantly higher absolute levels during the "city" compared to the "background" measurements, but also a very different temporal behaviour. While the "background" concentrations with almost no local sources of air pollutants have very constant levels with smooth time series, multiple sharp peaks of the various parameters are observed in the city due to numerous sources in the immediate vicinity of the sampling site. The strongest differences in the average concentrations (right panels) are observed for traffic-related parameters like nitrogen oxides, black carbon and organic and aromatic particle components. However, also for other parameter differences between the two sampling locations are observed, associated with the various sources in the city. Average particle number concentration levels are similar for both measurement locations. The lower "baseline" level in the city compared to the "background" measurement (apparently affected by additional sources further upwind) is balanced by multiple short and intense peaks. Due to the fact that the background measurement was performed exactly upwind of the city with exactly the same instrument setup used at the downtown site and the short delay between the two measurements the contribution of the city itself to local air composition can be calculated from this dataset. 


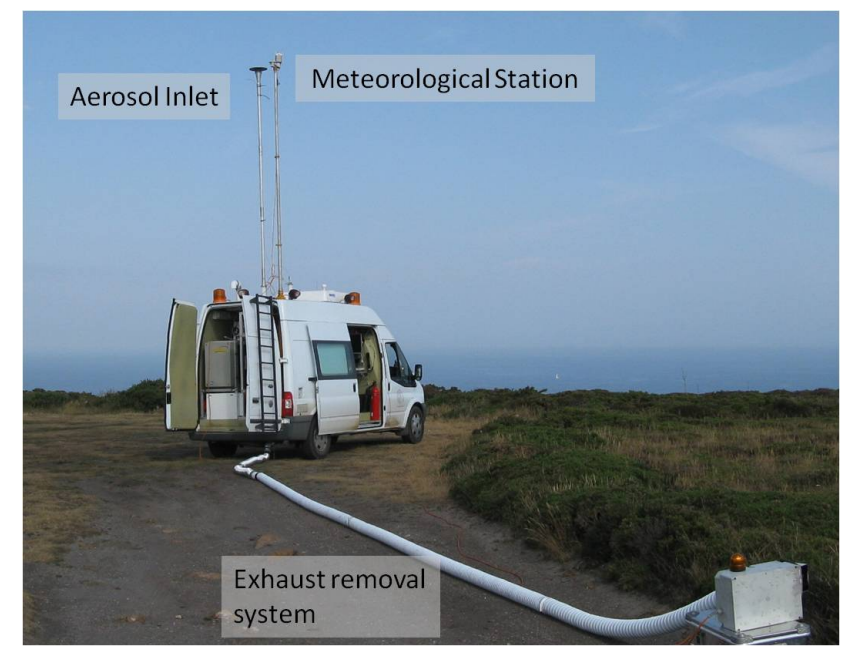

Fig. 6. The mobile laboratory during an autonomous stationary measurement at the coast in northern Spain during a field measurement campaign in June 2011. The engine's emissions are removed using the active exhaust removal system, which releases the pollutants $25 \mathrm{~m}$ downwind of the vehicle to avoid self-contamination.

\subsection{Mobile operation while driving}

The mobile laboratory is equipped with on-board power generation that allows measurements while the vehicle is driving. Typically, for such applications the upper front inlet is used. Compared to the lower front inlet it shows better sampling and transport performance and is less vulnerable to low-level dust.

Mobile measurements can be distinguished into three fundamentally different types:

Chasing measurements: mobile sources, like passenger vehicles, trucks or buses, but also airplanes during taxi on the airport, can be sampled over extended time intervals by chasing the emitters with the mobile laboratory (e.g., Canagaratna et al., 2004; Schneider et al., 2005). This allows measurement of their emissions under different ambient or operation conditions, like various engine loads under real-world driving conditions.

Mapping measurements: measurements of the ambient air while the mobile laboratory is driving provide information on pollutant concentrations along the driving track. If the complete measurement trip is completed before ambient conditions change significantly, these measurements reflect the spatial distribution of pollutants, and under favourable conditions allow the generation of pollutant maps. Figure 8 shows the distribution of black carbon (left panel) and particulate sulfate (right panel) along the $2500 \mathrm{~km}$ long trip from Mainz, Germany to southern Spain, the location of the DOMINO 2008 campaign (Diesch et al., 2011). Black carbon measurements are also available for the return trip, while the sulfate measurements were not performed during this part of the trip due to instrumental problems. Clearly the differences
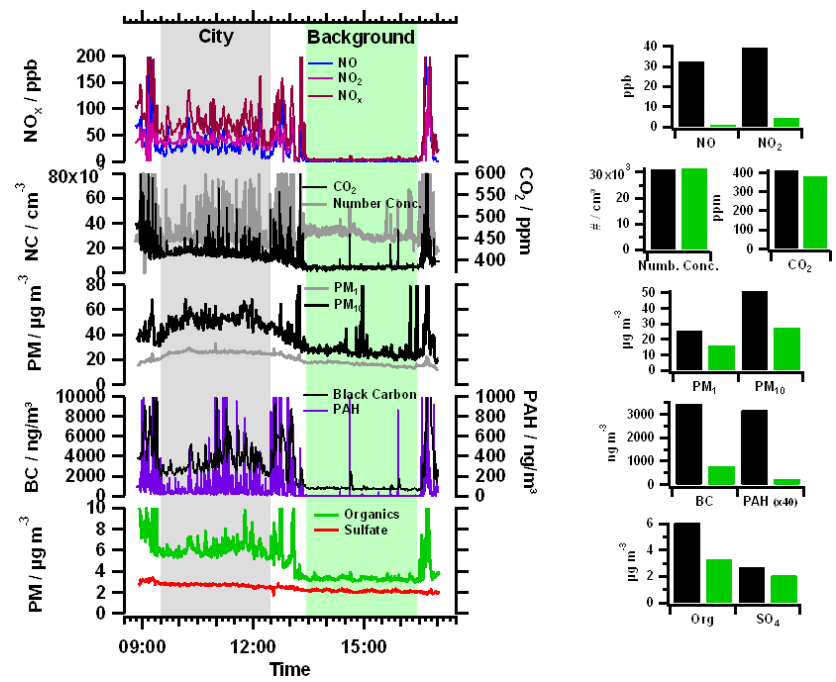

Fig. 7. Stationary measurements in downtown Mainz, Germany (grey shaded) and at a background site upwind of the city (green shaded) during a student's exercise in April 2011. Elevated concentrations and multiple short peaks of traffic-related pollutants are observed during the city-measurement (left panel). For most parameters average concentrations at the background site are significantly lower (right panels). NC: particle number concentration; BC: particulate black carbon, Org: particulate organics, $\mathrm{SO}_{4}$ : particulate sulfate.

in spatial distributions of these two air pollutants can be seen. Black carbon concentrations reflect the urban centers along the track quite well. However, no such dependence on population density can be observed in the sulfate distributions which reflect rather the sulfur emissions far upwind of the sampling locations than local source densities.

Other applications of mobile measurements are the investigation of pollutant distributions in the vicinity of major industrial sources or in residential areas within urban environments and the analysis of spatial structures of large emission plumes, e.g., from whole urban agglomerations like megacities (von der Weiden-Reinmüller et al., 2012).

Lagrangian measurements: for sufficiently well-known and stable meteorological and transport conditions it is possible to use the mobile laboratory to follow an air mass containing fresh emissions downwind along its transport path away from the source. Using this type of measurements it is possible to investigate atmospheric processes directly within this air mass, while emissions age, without a permanent change of the probed air mass. For this type of measurements as well as for all other mobile applications, careful planning of measurement trips and routes is essential to minimize local contamination. Otherwise these can easily dominate the measured concentrations over the targeted air masses, as detailed in the following section. 


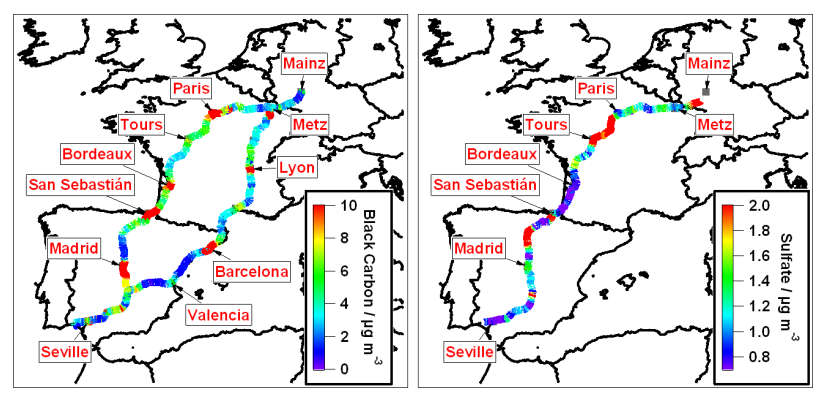

Fig. 8. Black carbon (left) and particulate sulfate (right) concentrations along the $2500 \mathrm{~km}$ trip from Mainz, Germany to southern Spain as part of the DOMINO field campaign in November 2008. While black carbon concentrations reflect the urban centers along the route quite well, sulfate has a more regional distribution. These differences reflect the sources and generation mechanisms of the two pollutants.

\section{Mobile laboratory measurement and data processing challenges}

Measurements with the mobile laboratory are often confronted with challenges that do not occur during "classical" field measurements. These challenges affect the operation of the instruments on-board the mobile laboratory as well as the proper analysis of the collected data.

\subsection{Heat and mechanical stress management of MoLa}

The mobile laboratory is intended for autonomous operation, both in stationary as well as in mobile applications. Therefore, limited resources like electrical power and consequently cooling capacity are available. Thermal management of the instrument compartment becomes a challenge under high ambient temperature conditions, especially when the vehicle is not moving and therefore external heat influx from solar radiation and additionally from the vehicle's engine is not efficiently removed. For efficient heat management all external vacuum pumps of instruments as well as the make-up flow pump are placed in a pump enclosure which is insulated from the instrument compartment. A blower is used to remove the pump exhaust together with the heat from the pumps out of the vehicle. In addition the hot exhaust of the AirPointer air conditioning unit is also conveyed through this pump box, further lowering the thermal load in the vehicle. Together with the air conditioning unit on the roof these measures are sufficient to enable measurements under the range of meteorological conditions, typically encountered in central Europe.

Further challenges for mobile operation are generated by mechanical shock impacts onto the instruments during driving of the mobile laboratory. Most of the instruments are rigidly mounted to the common instrument rack which is fixed to the vehicle without further shock mounts. However, the rear axle of the vehicle, located directly below the main instrument rack, is outfitted with an air suspension. Due to the large weight of the vehicle this suspension quenches shock impacts from driving very efficiently. So far almost no vibration-related instrument failures have been observed during more than $10000 \mathrm{~km}$ of mobile measurements.

\subsection{Measurement of short events}

While during stationary measurements meteorological conditions and concentrations of atmospheric compounds and pollutants change on time scales of minutes to hours, mobile measurements are characterised by fast changing concentration levels within short durations. When passing emission plumes of proximate sources elevated concentrations are typically observed for only a few seconds. Therefore, not only measurements with high temporal resolution but also exact synchronisation of the measurements with different instruments are essential for the proper analysis of such events. Data acquisition with one common acquisition software, running on the same computer assures identical time bases for all instruments. The actual sampling times can be determined by correcting for the aerosol residence time in the inlet system. The accuracy of these corrections is generally between one and several seconds. It is limited by individual instrument time constants and parabolic laminar flow velocity distributions within the sampling tubes that spread the arrival times of particles.

\subsection{Local contamination effects and filtering methods}

A major challenge in the analysis of data from mobile measurements is the treatment of local contaminations. Mobile measurements with a vehicle are intrinsically performed on streets where multiple sources of various emissions are located. If the mobile laboratory encounters such an emission plume the measured data will be dominated by the related single almost undiluted source, making it impossible to determine the real, undisturbed local concentrations. It is not always possible to avoid such contaminations of measurements, e.g., by driving along quiet back roads. Therefore, it is essential to identify data points affected by local contamination and to remove or correct them.

To clearly distinguish contamination plumes from the background, the time resolution of the measured parameter needs to be significantly shorter than the typical length of such an event. Our CPC particle number concentration measurements and $\mathrm{CO}_{2}$ measurements, both having a time resolution of one second, proved to be best suited for this analysis, with the particle number concentrations being advantageous over the $\mathrm{CO}_{2}$ concentrations due to their typically lower noise level. For the automatic identification of contamination events an approach was developed based on these tracers and on the statistically different behaviour of adjacent data points during background (uncontaminated) and pollution peak measurements. 
In the first step, the typical variability of concentration levels during background measurements is determined. For this purpose it is assumed that in a dataset where the contamination peaks are larger than the variation of the uncontaminated data, at least $50 \%$ of the data points are uncontaminated. From the data points below the median value only the standard deviation of the background $\sigma_{\mathrm{b}}$ is determined as the variability of the uncontaminated measurements. In the second step, contaminated data points are identified as those data points that differ more than $3 \sigma_{\mathrm{b}}$ (i.e., three times the typical variation) from adjacent background values. If a certain data point is identified as contaminated, the next point in the time series is evaluated using a slightly increased threshold level for identification of contamination. The increase in the threshold is determined using a random walk method (threshold $=3 \cdot \sigma_{\mathrm{b}}+\operatorname{sqrt}(n) \cdot \sigma_{\mathrm{b}}$, with $n$ number of data points since last uncontaminated point) and accounts for the normal temporal development of the background levels. At the end of this procedure all data points affected by local contamination are marked and can be eliminated from the dataset. In Fig. 9a, measured time series of $\mathrm{CO}_{2}$ mixing ratios from several mobile and intermediate stationary over-night measurements are shown as red trace together with particle number concentration measurements (green trace). Clearly multiple sharp peaks from local contamination sources can be seen in both time series. The blue trace in this figure is the filtered time series of the $\mathrm{CO}_{2}$ data where the algorithm has eliminated all points identified as contamination. While all sharp peaks have been removed from the dataset the algorithm seems to work well only during times when the density of contamination events is not too high (e.g., orange ovals). When too many contamination events are encountered within a limited time interval, the algorithm is not able to identify the background properly anymore and even in the filtered data increased concentration levels appear (e.g., green oval). In such cases other approaches are needed to identify uncontaminated data (see below). However, even under conditions with a moderate density of contamination events individual parameters are affected by local contamination to a different degree. While some of the contamination events mainly had an impact on particle number concentrations, others only affected $\mathrm{CO}_{2}$ levels (Fig. 9b). Therefore, scatter plots for combinations of parameters (Fig. 9c) are not necessarily a reliable approach for the identification of local contamination events.

This algorithm for the identification of contaminated data was compared with two approaches presented by Kolb et al. (2004). Their first method considers the probability distribution of measured concentrations and identifies values below the maximum of the Gaussian distribution as uncontaminated data. This method was applied to several datasets collected with the mobile laboratory and compared with the new approach. Both methods resulted in qualitatively similar filtered datasets. However, the results of the method by Kolb et al. (2004) were strongly dependent on the chosen number of bins of the probability distribution, especially for
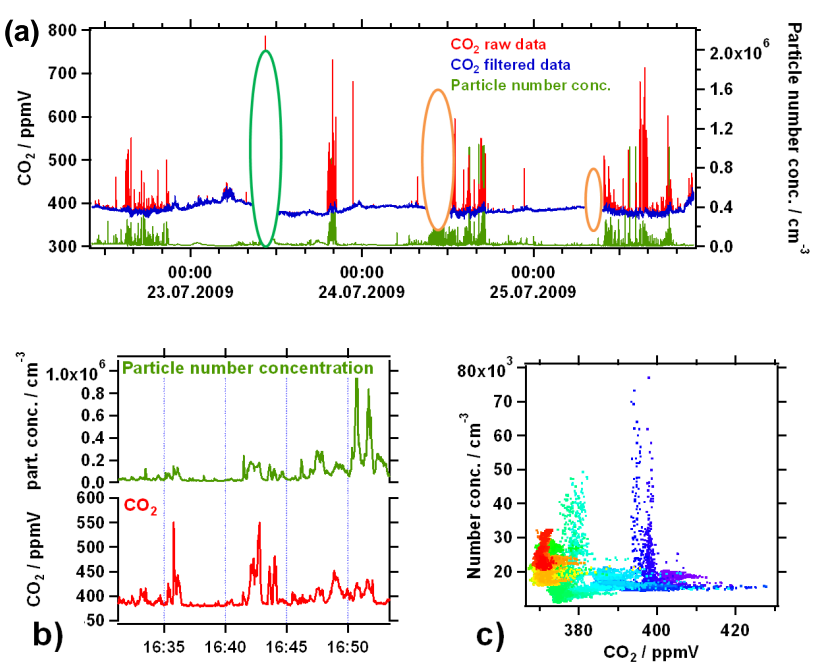

Fig. 9. Time series of mobile and intermediate stationary over-night particle number concentration and $\mathrm{CO}_{2}$ data from the MEGAPOLI summer field campaign in July 2009. The raw data (red and green traces) show many short peaks due to local contamination sources, which are efficiently removed in the filtered $\mathrm{CO}_{2}$ data (blue trace) using the contamination identification algorithm (a). The zoom-in (b) shows $20 \mathrm{~min}$ of high time resolution data from 20 July. Some of the contamination peaks appear mainly in the $\mathrm{CO}_{2}$ time series, others mainly in the particle number concentration data, resulting in separated branches in the scatter plot (c, color-coded by measurement time).

datasets with smaller number of values. In addition, this method failed to reliably determine the background values when two or more different air masses were probed within a single dataset, resulting in different background levels within the same set of data points.

The second method, described by Kolb et al. (2004) is a peak-background separation procedure. A "Rangemin" concentration is determined by replacing each point in the dataset with the minimum concentration encountered within a certain linear distance of that point. This method was not applicable to the MoLa datasets because local contamination peaks are often appearing with such high frequency that it is not possible to determine reliable background values. Also the height and length of these contamination peaks are varying strongly; therefore, applying this method onto such a dataset is more complicated or does not yield any meaningful results.

Also Bukowiecki et al. (2002) presented a method to automatically separate the background from peak concentrations, based on a percentile method. In that method the $5 \%$ percentile within each minute was chosen to reflect the uncontaminated background concentrations. The drawback of this method is that for minutes without contamination the resulting background concentrations will be biased low while for highly contaminated data ( $>95 \%$ of all data points contaminated, e.g., in heavy traffic) contamination will be regarded 
as background. In addition, this method provides a characteristic value for each one-minute interval, but does not identify contaminated time periods and, thus, cannot be used to correct for contamination in lower time-resolved data. Therefore, we did not further use this approach for our data.

Once the contaminated data points in the high time resolution data (e.g., number concentration or $\mathrm{CO}_{2}$ data) have been identified such a dataset can be used to filter other datasets which do not allow identification of such events directly (e.g., due to lower time resolution). Thus, all data points where more than a certain fraction of the respective 1-second data points are contaminated are also marked as contaminated data and are not used for further analysis.

Often the automatic method of identification of contamination events fails when the density of such events is too high, for example, when measuring in cities or in heavy traffic. Therefore, under such conditions a very labour-intensive method is used to define the uncontaminated data: by visual inspection of the videos recorded through the windshield during the mobile measurement and by manual marking of contamination events these can be identified and separated from time intervals without contamination.

In general, the analysis of mobile datasets is extremely time-consuming due to the fact that enormous amounts of data from multiple instruments have to be analysed and compared with each other. In order to make this analysis more effective adequate analysis tools are currently under development.

\section{Summary}

We have developed a mobile, ground based laboratory for efficient high-quality measurements of ambient air characteristics. While the focus of the measurements is on aerosol properties, also several trace gases and meteorological parameters are determined. The mobile laboratory is designed for both, stationary measurements as well as for truly mobile measurements, i.e., while the vehicle is driving.

Measurements on-board the mobile laboratory include physical aerosol parameters like particle number and mass concentration $\left(\mathrm{PM}_{1}, \mathrm{PM}_{2.5}, \mathrm{PM}_{10}\right)$ as well as particle size distributions from approximately $6 \mathrm{~nm}$ up to more than $30 \mu \mathrm{m}$. The chemical composition of the sub-micron aerosol can be determined by aerosol mass spectrometry (organics, sulfate, nitrate, ammonium, chloride), by photometric absorption measurements (black carbon), and by total particulate surface $\mathrm{PAH}$ analysis. In addition several trace gases $\left(\mathrm{O}_{3}, \mathrm{NO}, \mathrm{NO}_{2}, \mathrm{CO}, \mathrm{CO}_{2}, \mathrm{SO}_{2}, \mathrm{H}_{2} \mathrm{O}\right)$ are monitored. Finally, the most common meteorological parameters (wind direction and speed, ambient temperature, relative humidity, pressure, precipitation and solar radiation) are measured. All instruments have high time resolution, mostly in the range of a few seconds, with the exception of the aerosol mass spectrometer and the black carbon instrument, which measure with
30-60 s time resolution. The integration of additional instruments for special measurement purposes is anticipated.

Data acquisition with a common data acquisition computer and an unified measurement software allows the instrument operator a direct overview over the current ambient situation in real time. In addition, this approach supports efficient data analysis by providing all instrument data on a common time base and in a common data format.

During the development of the mobile laboratory special focus was laid on the optimization and characterisation of the aerosol inlet system regarding sampling- and transportrelated artifacts. The inlet system of the platform is optimized for low aerosol transport losses, resulting in negative biases in the relevant particle size ranges of the individual instruments of typically a few percent only. The residence times within the inlet systems are well known for the individual instruments, allowing for an accurate correction of the sampling times.

The mobile laboratory is equipped with three different aerosol inlets allowing different types of measurements: an upper and lower front inlet for mobile measurements and a roof inlet for stationary measurements. The roof inlet can quickly be set up for sampling at heights of up to $10 \mathrm{~m}$ above ground level. The meteorological station is fixed on an extendable mast to measure at the same height as aerosol sampling takes place. The vehicle is equipped with on-board electrical power generation sufficient for the instruments and air conditioning, directly powered by the vehicle's engine. For stationary measurements an active exhaust removal system transports the engine's emissions $25 \mathrm{~m}$ downwind of the sampling point, reliably avoiding self-contamination of the measurements.

With all these features the vehicle is capable of performing efficient high-quality research measurements. With the mobile laboratory a crew of two operators is capable of performing a full-scale research field campaign at arbitrary locations with little or no logistical preparation. Stationary measurements can be started within less than 10 min after arrival at any sampling point. With all these features it is possible to address a large range of scientific questions with this platform, like the investigation of anthropogenic emission sources, ranging from industrial facilities to megacities, the mapping of air pollutants, or the study of transport-related processes.

Data processing of the large and complex sets of measurement data remains a challenge. Especially the determination and treatment of local contamination in mobile data is time consuming. More efficient data analysis tools to extract the desired information from the multitude of measured parameters are currently under development. 
Acknowledgements. While most of the presented project was internally financed by the Max Planck Society through a "Grossgeraeteantrag", we acknowledge the EU Research Fund for Coal and Steel for partial funding of this work through the ASEMIS project (grant RFSR-CT-2009-00029). We thank James Allan, Scott Herndon, and Katja Dzepina for helpful discussions regarding the development of the data acquisition software and Johannes Fachinger for support in the inlet characterisation work. Finally, we are indebted to the electronic workshops of the MPIC and of the Institute of Physics of the Atmosphere at Gutenberg University Mainz as well as to the MPIC mechanical workshop, especially Wilhelm Schneider and Joachim Sody, for great support in the technical realisation of the mobile laboratory.

The service charges for this open access publication have been covered by the Max Planck Society.

Edited by: W. Maenhaut

\section{References}

Andronova, A. V., Granberg, I. G., Grisenko, A. M., Gubanova, D. P., Zudin, B. V., Iordanskii, M. A., Lebedev, V. A., Nevskii, I. A., and Obvintsev, Y. I.: Studies of the spatial and temporal distribution of surface aerosol along the trans-Siberian railroad, Izv. Atmos. Ocean. Phy.+, 39, S27-S34, 2003.

Belikov, I. B., Brenninkmeijer, C. A. M., Elansky, N. F., and Ral'ko, A. A.: Methane, Carbon Monoxide, and Carbon Dioxide Concentrations Measured in the Atmospheric Surface Layer over Continental Russia in the TROICA Experiments. Izvestiya, Atmos. Ocean. Phys., 42, 46-59, 2006.

Belosi, F., Contini, D., Donateo, A., and Prodi, F.: Measurements of atmospheric aerosol in the Salentum Peninsula and its correlation with local meteorology, Nuovo Cimento C, 29, 473-486, 2006.

Brands, M., Kamphus, M., Böttger, T., Schneider, J., Drewnick, F., Roth, A., Curtius, J., Voigt, C., Borbon, A., Beekmann, M., Bourdon, A., Perrin, T., and Borrmann, S.: Characterization of a Newly Developed Aircraft-Based Laser Ablation Aerosol Mass Spectrometer (ALABAMA) and First Field Deployment in Urban Pollution Plumes over Paris During MEGAPOLI 2009, Aerosol Sci. Tech., 45, 46-64, 2011.

Bukowiecki, N., Dommen, J., Prévot, A. S. H., Richter, R., Weingartner, E., and Baltensperger, U.: A mobile pollutant measurement laboratory - measuring gas phase and aerosol ambient concentrations with high spatial and temporal resolution, Atmos. Environ., 36, 5569-5579, 2002.

Canagaratna, M. R., Jayne, J. T., Ghertner, D. A., Herndon, S., Shi, Q., Jimenez, J. L., Silva, P. J., Williams, P., Lanni, T., Drewnick, F., Demerjian, K. L., Kolb, C. E., and Worsnop, D. R.: Chase Studies of Particulate Emissions from in-use New York City Vehicles, Aerosol Sci. Tech., 38, 555-573, 2004.

Cocker III, D. R., Shah, S. D., Johnson, K., Miller, J. W., and Norbeck, J. M.: Development and Application of a Mobile Laboratory for Measuring Emissions from Diesel Engines. 1. Regulated Gaseous Emissions, Environ. Sci. Technol., 38, 2182-2189, 2004a.

Cocker III, D. R., Shah, S. D., Johnson, Z., Xiaona, K., Miller, J. W., and Norbeck, J. M.: Development and Application of a Mo- bile Laboratory for Measuring Emissions from Diesel Engines. 2. Sampling for Toxics and Particulate Matter, Environ. Sci. Technol., 38, 6809-6816, 2004b.

Davidson, C. I., Phalen, R. F., and Solomon, P. A.: Airborne Particulate Matter and Human Health: A Review, Aerosol Sci. Tech., 39, 737-749, 2005.

DeCarlo, P. F., Kimmel, J. R., Trimborn, A., Northway, M. J., Jayne, J. T., Aiken, A. C., Gonin, M., Fuhrer, K., Horvath, T., Docherty, K. S., Worsnop, D. R., and Jimenez, J. L.: Field-Deployable, High-Resolution, Time-of-Flight Aerosol Mass Spectrometer, Anal. Chem., 78, 8281-8289, 2006.

Diesch, J.-M., Drewnick, F., Zorn, S. R., von der WeidenReinmüller, S.-L., Martinez, M., and Borrmann, S.: Variability of aerosol, gaseous pollutants and meteorological characteristics associated with continental, urban and marine air masses at the SW Atlantic coast of Iberia, Atmos. Chem. Phys. Discuss., 11, 31585-31642, doi:10.5194/acpd-11-31585-2011, 2011.

Drewnick, F., Hings, S. S., DeCarlo, P., Jayne, J. T., Gonin, M., Fuhrer, K., Weimer, S., Jimenez, J. L., Demerjian, K. L., Borrmann, S., and Worsnop, D. R.: A New Time-of-Flight Aerosol Mass Spectrometer (TOF-AMS) - Instrument Description and First Field Deployment, Aerosol Sci. Tech., 39, 637-658, 2005.

Drewnick, F., Hings, S. S., Alfarra, M. R., Prevot, A. S. H., and Borrmann, S.: Aerosol quantification with the Aerodyne Aerosol Mass Spectrometer: detection limits and ionizer background effects, Atmos. Meas. Tech., 2, 33-46, doi:10.5194/amt-2-332009, 2009.

Elanskii, N. F., Belikov, I. B., Golitsyn, G. S., Grisenko, A. M., Lavrova, O. V., Pankratova, N. V., Safronov, A. N., Skorokhod, A. I., and Shumskii, R. A.: Observations of the atmosphere composition in the Moscow megapolis from a mobile laboratory, Dokl. Earth Sci., 432, 649-655, 2010.

Herndon, S. C., Jayne, J. T., Zahniser, M. S., Worsnop, D. R., Knighton, B., Alwine, E., Lamb, B. K., Zavala, M., Nelson, D. D., McManus, J. B., Shorter, J. H., Canagaratna, M. R., Onasch, T. B., and Kolb, C. E.: Characterization of urban pollutant emission fluxes and ambient concentration distributions using a mobile laboratory with rapid response instrumentation, Faraday Discuss., 130, 327-339, 2005.

Kamphus, M., Ettner-Mahl, M., Brands, M., Curtius, J., Drewnick, F., and Borrmann, S.: Comparison of Two Aerodynamic Lenses as an Inlet for a Single Particle Laser Ablation Mass Spectrometer, Aerosol Sci. Tech., 42, 970-980, 2008.

Kittelson, D., Johnson, J., Watts, W., Wei, Q., Drayton, M., Paulsen, D., and Bukowiecki, N.: Diesel Aerosol Sampling in the Atmosphere, SAE Technical Paper Series, No. 2000-01-2212, 2000.

Kolb, C. E., Herndon, S. C., McManus, J. B., Shorter, J. H., Zahniser, M. S., Nelson, D. D., Jayne, J. T., Canagaratna, M. R., and Worsnop, D. R.: Mobile Laboratory with Rapid Response Instruments for Real-Time Measurements of Urban and Regional Trace Gas and Particulate Distributions and Emission Source Characteristics, Environ. Sci. Technol., 38, 5694-5703, 2004.

Kunkel, D., Lawrence, M. G., Tost, H., Kerkweg, A., Jöckel, P., and Borrmann, S.: Urban emission hot-spots as sources for remote aerosol deposition, Geophys. Res. Lett., 39, L01808, doi:10.1029/2011GL049634, 2012.

Maciejczyk, P. B., Offenberg J. H., Clemente, J., Blaustein, M., Thurston, G. D., and Chen, L. C.: Ambient pollutant concentrations measured by a mobile laboratory in South Bronx, NY, 
Atmos. Environ., 38, 5283-5294, 2004.

McMurry, P.: A review of atmospheric aerosol measurements, Atmos. Environ., 34, 1959-1999, 2000.

Mohr, C., Richter, R., DeCarlo, P. F., Prévôt, A. S. H., and Baltensperger, U.: Spatial variation of chemical composition and sources of submicron aerosol in Zurich during wintertime using mobile aerosol mass spectrometer data, Atmos. Chem. Phys., 11, 7465-7482, doi:10.5194/acp-11-7465-2011, 2011.

Pirjola, L., Parviainen, H., Hussein, T., Valli, A., Hämeri, K., Aaalto, P., Virtanen, A., Keskinen, J., Pakkanen, T. A., Mäkelä, T., and Hillamo, R. E.: "Sniffer" - a novel tool for chasing vehicles and measuring traffic pollutants, Atmos. Environ., 38, 36253635, 2004

Pirjola, L., Kupiainen, K. J., Perhoniemi, P., Tervahattu, H., and Vesala, H.: Non-exhaust emission measurement system of the mobile laboratory SNIFFER, Atmos. Environ., 43, 4703-4713, 2009.

Pöschl, U.: Atmospheric aerosols: composition, transformation, climate and health effects, Angew. Chem. Int. Edit., 44, 7520-7540, 2005.

Rinke, R., Wieser, A., Vogel, B., Corsmeier, U., and Kottmeier, Ch.: Messungen der räumlichen Variabilität der Luftqualität in einem Ballungsraum mittels einer Straßenbahn, Progress report 2010 for BWPLUS project; available at: http://www.aero-tram.kit.edu (last access: 25 June 2012), 2010.

Schneider, J., Hock, N., Weimer, S., Borrmann, S., Kirchner, U., Vogt, R., and Scheer, V.: Nucleation particles in Diesel exhaust: Composition inferred from in-situ mass spectrometric analysis, Environ. Sci. Technol., 39, 6153-6161, 2005.

Schneider, J., Kirchner, U., Borrmann, S., Vogt, R., and Scheer, V.: In situ measurements of particle number concentration, chemically resolved size distributions and black carbon content of traffic-related emissions on German motorways, rural roads and in city traffic, Atmos. Environ., 42, 4257-4268, 2008.

Solomon, S., Quin, D., Manning, M., Chen, Z., Marquis, M., Averyt, K. B., Tignor, M., and Miller, H. L.(Eds.): Climate Change 2007: The Physical Science Basis. Cambridge University Press, Cambridge, UK, 2007.

Thornhill, D. A., de Foy, B., Herndon, S. C., Onasch, T. B., Wood, E. C., Zavala, M., Molina, L. T., Gaffney, J. S., Marley, N. A., and Marr, L. C.: Spatial and temporal variability of particulate polycyclic aromatic hydrocarbons in Mexico City, Atmos. Chem. Phys., 8, 3093-3105, doi:10.5194/acp-8-3093-2008, 2008.
Vogt, R., Kirchner, U., Scheer, V., Hinz, K. P., Trimborn, A., and Spengler, B.: Identification of diesel exhaust particles at an Autobahn, urban and rural location using single-particle mass spectrometry, J. Aerosol Sci., 34, 319-337, 2003.

von der Weiden, S.-L.: Development and Characterization of the Aerosol Inlet System for the Mobile Laboratory "MoLa", Diploma thesis, Johannes Gutenberg University Mainz, 2008.

von der Weiden, S.-L., Drewnick, F., and Borrmann, S.: Particle Loss Calculator - a new software tool for the assessment of the performance of aerosol inlet systems, Atmos. Meas. Tech., 2, 479-494, doi:10.5194/amt-2-479-2009, 2009.

von der Weiden-Reinmüller, S.-L., Drewnick, F., Crippa, M., Prevôt, A. S. H., Meleux, F., Böttger, T., Klimach, T., Zorn, S. R., Diesch, J.-M., Baltensperger, U., Beekmann, M., and Borrmann, S.: On the applicability of mobile aerosol and trace gas measurements for the investigation of characteristics and transformation of megacity emissions: The Paris metropolitan area, in preparation, 2012.

Wang, M., Zhu, T., Zheng, J., Zhang, R. Y., Zhang, S. Q., Xie, X. X., Han, Y. Q., and Li, Y.: Use of a mobile laboratory to evaluate changes in on-road air pollutants during the Beijing 2008 Summer Olympics, Atmos. Chem. Phys., 9, 8247-8263, doi:10.5194/acp-9-8247-2009, 2009.

Wa Tang, U. and Wang, Z.: Determining Gaseous Emission Factors ond Driver's Particle Exposures during Traffic Congestion by Vehicle-Following Measurement Techniques, J. Air Waste Ma., 56, 1532-1539, 2006.

Weijers, E. P., Khlystov, A. Y., Kos, G. P. A., and Erisman, J. W.: Variability of particulate matter concentrations along roads and motorways determined by a moving measurement unit, Atmos. Environ., 38, 2993-3002, 2004.

Weimer, S., Mohr, C., Richter, R., Keller, J., Mohr, M., Prevot, A. S. H., and Baltensperger, U.: Mobile measurements of aerosol number and volume size distributions in an Alpine valley: Influence of traffic versus wood burning. Atmospheric Environment, 43, 624-630, 2009. 